\title{
Reciprocating wear test of dental composites against human teeth and glass
}

\author{
A. Ramalho ${ }^{a, 1}$, P. Vale Antunes ${ }^{b, *}$ \\ a ICEMS, Departamento de Engenharia Mecânica, Faculdade de Ciências e Tecnologia da, Universidade de Coimbra, \\ Pinhal de Marrocos, 3030-788 Coimbra, Portugal \\ ${ }^{\mathrm{b}}$ Escola Superior de Tecnologia, Instituto Politécnico de Castelo Branco, Av. do Empresário, \\ 6000-767 Castelo Branco, Portugal
}

Received 27 August 2006; received in revised form 28 December 2006; accepted 1 January 2007 Available online 23 May 2007

\begin{abstract}
The complexity of the contact in the mouth leads to an interplay of sliding wear, abrasion and fatigue, independently of the surfaces in contact, which involve either tooth-to-tooth or tooth-to-restoration. Since this is a complex problem and in vivo tests are expensive, much time consuming and the generalization of the attained results very complex, in vitro simulations are the usual research approach.

The aim of this study was focused on in vitro fiction-wear tests of dental composites under sliding reciprocating. Tests were done involving human teeth and glass spheres tested against a commercial composite. The main idea was to characterize a commercial composite emphasizing the influence of two different antagonists: glass spheres and human teeth. An energetic approach was used to relate the wear/energy of the pairs, teeth-composite and glass-composite. In order to determine this relationship between both pairs, materials tests were conducted for several normal load conditions and different durations. This allowed determining the usual value of wear coefficient of both pairs of materials and their energetic relationships. Not only was evaluated the wear on the composites but also the antagonist as well. The removal mechanisms involved in the wear process are discussed while taking into account the systematic SEM observations to evaluate the wear mechanisms.
\end{abstract}

(C) 2007 Elsevier B.V. All rights reserved.

Keywords: Enamel wear; Reciprocating test; Energetic approach

\section{Introduction}

The two most important elements of the tooth, from the tribological point of view, are the outer enamel layer and the dentine, which lies underneath. The enamel is initially exposed to the loads and chemical environment within the mouth as a result of chewing, etc. If this layer is breached due to tooth fracture or wear the underlying dentine is left exposed. Enamel is thicker at the tip of each tooth $(2-3 \mathrm{~mm})$ and reduces its thickness at the cemento-enamel junction [1].

Tooth enamel, whose main properties are summarized in Table 1 , is a unique natural substance, which still cannot be effectively replaced by artificial restorative materials. Its most important attribute is a good wear resistance, despite severe

\footnotetext{
* Corresponding author. Tel.: +351 272339 300; fax: +351 272339399 .

E-mail addresses: amilcar.ramalho@dem.uc.pt (A. Ramalho), pedrov@est.ipcb.pt (P.V. Antunes)

${ }^{1}$ Tel.: +351 239 790700; fax: +351239790701.
}

working conditions, such as widely ranging loads, reciprocating movements, temperature shocks, impacts or possible acid attacks [2]. Sound enamel under friction coming from mastication and biting loses only $10-40 \mu \mathrm{m}$ thick layer per year [3], while average wear rate found for restorative dental materials in clinical conditions ranges from 8 to $9 \mu \mathrm{m}$ per month [4]. This is the main reason why many researchers try to understand the good wear performance of enamel.

Table 1 summarizes the relevant mechanical properties of enamel [1].

Thus, to investigate the wear of dental restorative materials against enamel is a fundamental step towards obtaining highperformance new materials. Clinical trials could certainly be the best option to determine materials wear characteristics; however, such trials are expensive and time consuming. Preliminary testing applying an in vitro approach is therefore a cheap and effective way to characterize new potential restorative materials.

The major challenge to develop a laboratory test program, whose results could be accurately used to predict the wear 
Table 1

Mechanical properties of enamel

\begin{tabular}{ll}
\hline Elastic modulus $(\mathrm{GPa})$ & $20-84.2$ \\
Shear modulus $(\mathrm{GPa})$ & 29 \\
Bulk modulus $(\mathrm{GPa})$ & 45,65 \\
Poisson's ratio & $0.23,0.30$ \\
Compressive strength $(\mathrm{MPa})$ & $95-386$ \\
Tensile strength $(\mathrm{MPa})$ & $30-35$ \\
Shear strength $(\mathrm{MPa})$ & 60 \\
Hardness $(\mathrm{Knoop}$ indenter $)(\mathrm{MPa})$ & $2500-5000$ \\
Density $\left(\mathrm{kg} / \mathrm{m}^{3}\right)$ & 2500
\end{tabular}

behaviour in component, or biological practical cases, is certainly the selection of the type of contact, the relative movement and the operating variables.

The complexity of the tooth contact makes even more difficult to establish the most suitable technique. Different simple test types have been adopted [5-23]. Some investigators use contacts with complex movement more similar to what happens in the mouth, using cycles with complex loads and paths attaining different wear types. These wear apparatus with elaborated movements are more similar to the tooth contact, however make difficult to determine which wear mechanism produces a specific damage, and it is almost impossible to extrapolate or compare results attained with different equipments. It is worth mentioning that in vitro studies present the great advantage of allowing the control over the variables in study, thus permitting more reliable wear results. The major disadvantage of in vitro tests is the difficulty to transpose the results to practical cases.

The aim of the present work is to investigate the wear behaviour of a commercial dental composite tested either against human teeth and glass spheres. The ultimate goal of this kind of studies is to establish the possibility to predict the wear behaviour of the pair tooth-composite based on the results of laboratory tests involving the contact of the composite with synthetic material.

\section{Experimental procedures}

\subsection{Materials and specimens}

For the present study was selected a highly filled packable resin-based composite named Surefil (Dentsply, De Trey, Konstanz, Germany; Table 2). Fig. 1 presents the morphology of this condensable composite material, which is suitable for posterior restorations. The image was taken by SEM and the dimension of the reinforcing particles can be clearly observed. The average

Table 2

Composition of the packable resin composite matrix used in this work: type, dimension and volume fraction of the reinforcement filler particles

\begin{tabular}{ll}
\hline Brand name & Surefil \\
Matrix & Urethane modified Bis-GMA \\
Filler type & Barium, silica glass \\
Average filler size $(\mu \mathrm{m})$ & 0.8 \\
Filler weight $(\%)$ & 82 \\
Filler volume $(\%)$ & 66 \\
\hline
\end{tabular}

Bis-GMA, bisphenol A polyethylene glycol diether dimethacrylate.

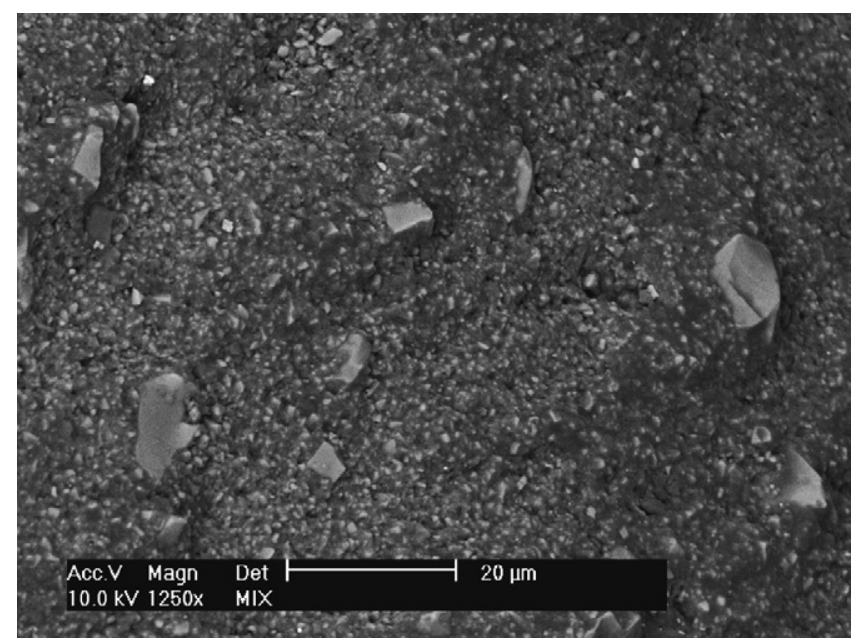

Fig. 1. Morphology of the commercial composite observed by SEM.

particle size of the composite is $0.8 \mu \mathrm{m}$; however, the scatter of the particle tail is significant and some particles can measure up to $15 \mu \mathrm{m}$.

Disc-shape specimens of composite, with $10 \mathrm{~mm}$ in diameter and $2 \mathrm{~mm}$ thickness, were obtained using an aluminium mould. The mould was placed on a transparent film, resting on a glass, manually filled with a slight excess of resin composite and covered in the same manner as the base. Before curing, the composite samples were manually compacted applying light finger pressure on the upper glass. A Kerr ${ }^{\circledR}$ polymerisation unit, the Optilux 501, was used to perform this task. The output wave length range of the curing light varies from 400 to $510 \mathrm{~nm}$, and the minimum light intensity is $850 \mathrm{~mW} / \mathrm{cm}^{2}$, using an $8 \mathrm{~mm}$ curved turbo light guide (information taken from the technical description of the manufacturer). The tip of the light guide was placed in contact with the upper glass in order to avoid scattering the light, and curing time was $40 \mathrm{~s}$. The polymerisation unit ensures a curing depth greater than the thickness of the specimens.

In terms of mechanical properties the processed composite specimens, after cure, were characterized by a micro-hardness of $935 \mathrm{MPa}$ and a standard deviation of 37. Prior to wear test, the specimens cure face were polished with abrasive paper up to grit 2500 . The average $R_{\mathrm{a}}$ roughness was of $0.23 \mu \mathrm{m}$ with a standard deviation of 0.02 for six measurements.

Reciprocating wear tests were carried out testing the composite material against spherical ended specimens of two different materials: glass and human pre-molar teeth. The glass spheres (Kugelfabrik Gebauer GmbH, Fulda, Germany) used as counterbody were standard in accordance with DIN 5401 part 2, concerning the control in the geometry and dimensions (Table 3 ).

The teeth used in the present study were sound premolar extracted for mainly orthodontic reasons, and were supplied by the Faculty of Medicine of Coimbra University. All the teeth were properly washed and stored until its usage. In all of them the hardness, Vickers indenter, was measured in 10 different locations of the enamel layer. The average hardness, in 30 teeth, was $3325 \mathrm{MPa}$ with standard deviation (S.D.) of 434. Concerning the teeth roughness, in the location where the contact was 
Table 3

Characteristics of glass spheres and dimensions

\begin{tabular}{ll}
\hline Material & Soft glass \\
Density $\left(\mathrm{kg} / \mathrm{m}^{3}\right)$ & 2500 \\
Hardness $(\mathrm{MPa})($ S.D. $)$ & $5177(116)$ \\
Average diameter $(\mathrm{mm})$ & 10 \\
Diameter tolerance $(\mu \mathrm{m})$ & 14 \\
\hline
\end{tabular}

effectuated, $R_{\mathrm{a}}$ was of $0.09 \mu \mathrm{m}$ (S.D., 0.01). The high value of standard deviation in the determination of micro-hardness expresses one of the inconveniences of biological materials usage.

For the tests with human teeth a preparation was required in order to obtain the desired geometry. So as to guarantee similar contact geometry between both pairs of materials, the teeth were prepared to ensure a radius of $5 \mathrm{~mm}$ in the contact surface. This preparation consisted in removing the teeth's root and each tooth was cut in half. Afterwards, each one of these halves was glued in acrylic cylinders and put in contact with a rotating mould with the desired radius. Applying a constant pressure to the contact and adding abrasive pastes of several granulometries permitted to attain the desired shape. Each one of the teeth was polished with zircon powder against felt in order to remove the scratches produced by the abrasive pastes.

\subsection{Wear tests}

After considering all aspects that the wear experiments involved and which were presented in the introduction, the selected wear test was of the reciprocating type, with contact geometry plane-sphere. This type of test was selected firstly due to similitude with the natural movement occurred in the mouth and secondly also because it allows variations in the amplitude of movement, normal load and test environment. The possibility of evaluating the wear of both materials in contact is also an important advantage of this type of tests.

The geometry of the contact was plane-sphere, with reciprocating motion in distilled water bath. Both antagonist bodies used had a $5 \mathrm{~mm}$ radii; this value was selected because it corresponds to the average curvature radius of molar teeth [24].

(a)

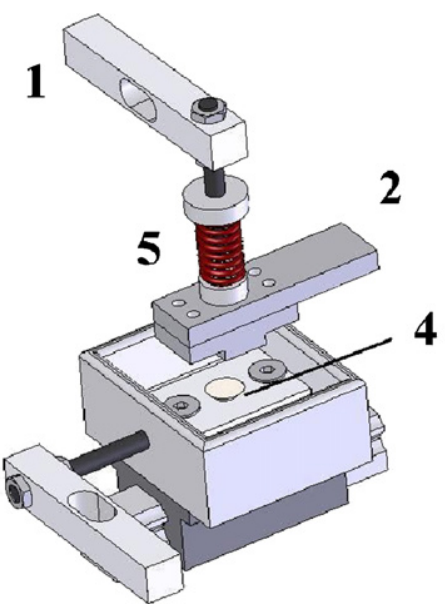

The reciprocating test was performed to determine the wear resistance of the chosen composite material and to evaluate the wear produced in the antagonist bodies. This technique comprises a sliding contact of a spherical body in reciprocating motion against a flat specimen of composite material (Fig. 2).

In Fig. 2 are indicated the elements that constitute the reciprocating apparatus. The sphere or tooth (7) is connected to the moving stage (2) and is kept in permanent contact against the horizontal surface of the stationary specimen (4). The normal load is applied by a spindle-spring (5), which is connected to the normal load cell (1) to measure the normal applied force. In the scope of the present study, the values of normal load applied to the contact, glass-composite or tooth-composite, were 3, 5, 6 and $8 \mathrm{~N}$. An harmonic wave generated by an eccentric and rod mechanism that was set with stroke length of $2 \mathrm{~mm}$ and frequency of $1 \mathrm{~Hz}$ [1] imposed a reciprocating movement to the upper specimen carrier (2). The composite specimen was placed in a container, which was filled with distilled water (6). The lower specimen holder was connected to a ball linear bearing slider to allow movement in the direction of the motion. A stationary load cell (3) is used to equilibrate the lower specimen attaining the friction force values along the test.

During the chewing process of human beings, the magnitude of mastigatory force in the oral cavity ranges from 3 to $36 \mathrm{~N}$ [25]. According to the current study, the surfaces interact theoretically by point contact; therefore, the normal load was fixed near the minimum referred values and also because the tests are of large duration and, during chewing, the highest loads occur in the mouth only sporadically.

The values of duration test for both pairs of materials, glass-composite and tooth-composite were selected, first, through an evaluation of the wear marks. Due to the fact that typically the tooth produces a smaller associated damage, in itself and in the composite, the test duration for this pair of materials varied from 6000 to 20,000 cycles. Previous studies revealed that, especially for low normal loads, duration of less than 6000 cycles did not allow, on composites and counterbody, a wear volume that was sufficient to be visualized and measured.

(b)

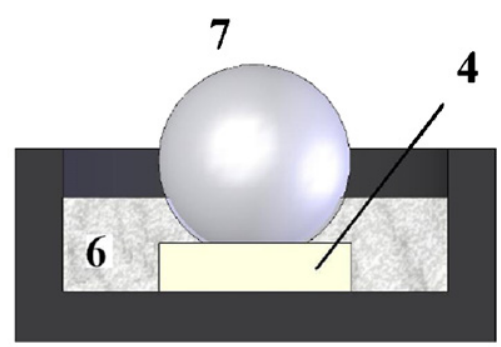

Fig. 2. Reciprocating equipment for sphere-plane contact. 


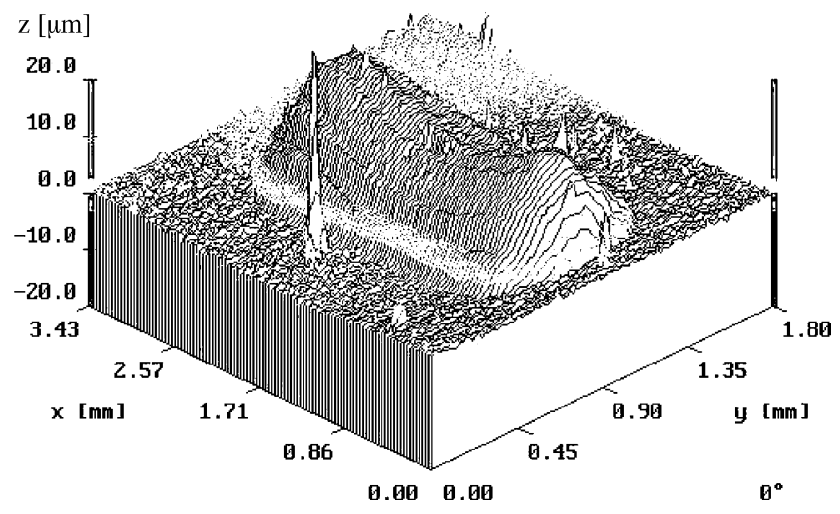

Fig. 3. 3D profiles of the composite wear mark (the image show the profiles inverted).

Concerning the pair glass-composite, the duration ranged from 2000 to 12,000 . For this pair of materials, these durations were combined with the values of normal load: $3,5,6$, and $8 \mathrm{~N}$.

In all cases the reciprocating tests were done in distilled water bath at room temperature.

Table 4 resumes all the test conditions used for both pairs of materials. The tests were sorted by the increasing energy input. The product of load by number of cycles was considered as a degree of severity of the test.

After testing the scar produced on the composite specimens were scanned by Roddenstock RM 600 laser stylus (Fig. 3). The scanning of all the tested specimens was transversal to the sliding direction and the distance between profiles ranged from 18 to $25 \mu \mathrm{m}$, depending on the length of the wear scar. The areas of the 2D profiles were integrated along the length of the wear mark, allowing the determination of the volume removed by wear of composite dental material [26]. The wear volume of the counterbody, glass sphere and teeth presented a spherical-caps shape and the diameter of their surface was measured in two orthogonal directions: the direction of motion and the direction perpendicular to it. The average values of crater radius, $r$, as well as the sphere radius, $R$, were then used to calculate the depth, $h$, and volume, $V$, of removed material, using suitable equations well described elsewhere [27].

The energy dissipated by friction between the bodies in contact can be considered the major source of wearability of materials in sliding contacts. Energy dissipated by friction generates wear damage, for instance in cases of fracturing, plastic deformation or tribochemical reactions. Thus, the energy dissipation could be directly associated with the wear. According to Czicos [28], concepts similar to thermodynamic analysis could be applied, at least at a qualitative level, to the ball-on-flat bidirectional contact type. From the energetic approach the energy dissipation by friction along the test is directly proportional to the wear volume $[29,30]$.

The tangential force to calculate the dissipated energy was obtained through periodic acquisition along every test. The energy dissipation, which is therefore associated to the wear in each test, is computed along the test as the work of the tangential force

The interval between acquisitions was made of 300 cycles and a vector of 3000 values was saved per acquisition. Three loops of time-force were computed at least in each acquisition. These values allow the calculation of the average work between acquisitions. Integrating the average work along the tests time permitted to obtain the total energy dissipated by friction. The values of energy were then correlated with the volume of material removed during the tests. This approach was applied both to the composite and the antagonist. For each one of the acquisitions the average tangential force (the root mean square average) was also calculated. After attaining a steadystate regime the average tangential force of every acquisition was used to calculate the friction coefficient.

The surface of the wear marks was examined by SEM. All the tested specimens were sputter-coated with gold in order to allow a better observation. The images were attained with secondary and backscattered electron detectors to allow the observation of the particles dimension and distribution and the identification of the wear mechanisms occurred in the tests.

\section{Results and morphology}

\subsection{Pair glass-composite}

The values of wear of the composite and antagonist increase generally with the product of normal load by number of cycles. Thus, different amounts of wear were generated as a function

Table 4

Test conditions used in the characterization of the two pairs of material

\begin{tabular}{|c|c|c|c|c|c|}
\hline \multicolumn{6}{|l|}{ Material pair } \\
\hline \multicolumn{3}{|c|}{ Glass sphere-composite } & \multicolumn{3}{|l|}{ Tooth-composite } \\
\hline Test designation & Normal load (N) & Duration (cycles) & Test designation & Normal load $(\mathrm{N})$ & Duration (cycles) \\
\hline $\mathrm{B}$ & 3 & 6,000 & $\mathrm{~K}$ & 5 & 10,500 \\
\hline C & 5 & 6,000 & $\mathrm{~L}$ & 6 & 10,000 \\
\hline D & 8 & 4,000 & M & 3 & 20,000 \\
\hline G & 5 & 10,500 & $P$ & 6 & 20,000 \\
\hline $\mathrm{H}$ & 8 & 9,000 & - & - & - \\
\hline I & 8 & 12,000 & - & - & - \\
\hline
\end{tabular}




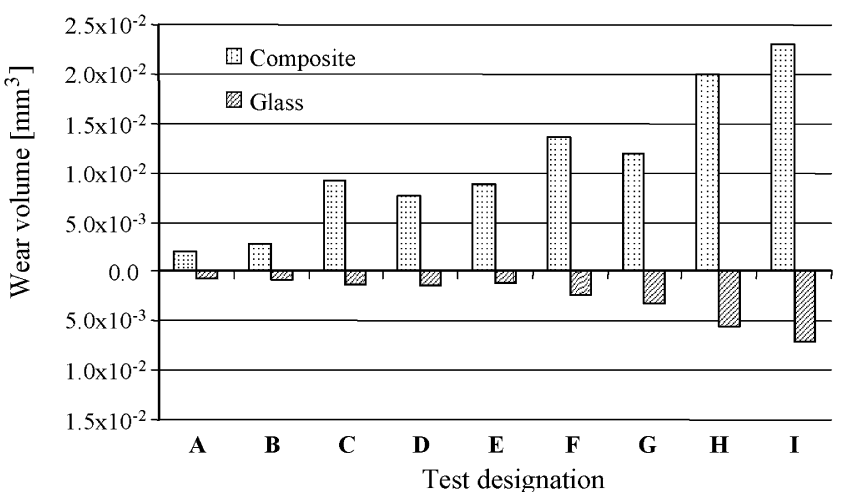

Fig. 4. Wear volumes of the restorative material and antagonist body, glass sphere, reciprocating test with distillate water.

of the test conditions. Fig. 4 displays the obtained results for both composite and antagonist; the lower part of the graphic corresponds to the glass spheres wear, while the upper part represents the composite wear. The tests were classed from A to I by increasing test severity and in general the wear amount fits the same sort. Exceptions are tests $\mathrm{C}$ and $\mathrm{F}$. Test $\mathrm{C}$ presents a higher value of the composite volume than $\mathrm{D}$ and $\mathrm{E}$. Test $\mathrm{F}$, which has a more normal load, although the number of cycles is smaller, attains 6000 against the 10,500 of test G. The values of wear measured for the antagonist body, the glass sphere, shows almost the same evolution as the one verified in the wear volume of the composite. It was generally observed an increase of the wear volume with the rise of product normal load by number of cycles.

In Fig. 5 are represented the average value of the friction force (the root mean square value) plotted against the normal applied load, for the pair glass-composite, where $R^{2}$ represents the correlation factor for the linear fitting of the data. The results clearly fit reasonably into a linear evolution; this pair agrees therefore with the Amontons-Coulomb linear behaviour, and the slope of the straight line fitted by the experimental results constitutes a good approach to the friction coefficient. In this case a value of 0.19 was obtained.

Table 5 presents, for all the tests of the pair composite-glass, the average friction coefficients calculated from the average value of the tangential force during each test, with the obtained values ranging from 0.19 to 0.27 .

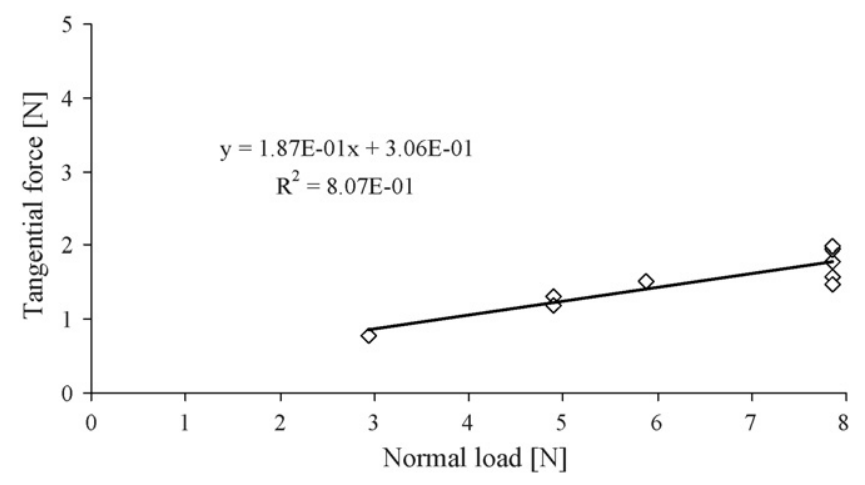

Fig. 5. Representation of friction coefficient for the pair glass-composite.
Table 5

Representation of friction coefficient for the pair glass-composite

\begin{tabular}{llcl}
\hline Test designation & $\begin{array}{l}\text { Normal } \\
\text { load }(\mathrm{N})\end{array}$ & $\begin{array}{l}\text { Duration } \\
\text { (cycles) }\end{array}$ & $\begin{array}{l}\text { Average friction } \\
\text { coefficient, } \mu\end{array}$ \\
\hline A & 8 & 2,000 & 0.20 \\
B & 3 & 6,000 & 0.26 \\
C & 5 & 6,000 & 0.27 \\
D & 8 & 4,000 & 0.19 \\
E & 6 & 6,000 & 0.26 \\
F & 8 & 6,000 & 0.23 \\
G & 5 & 10,500 & 0.24 \\
H & 8 & 9,000 & 0.25 \\
I & 8 & 12,000 & 0.25 \\
\hline
\end{tabular}

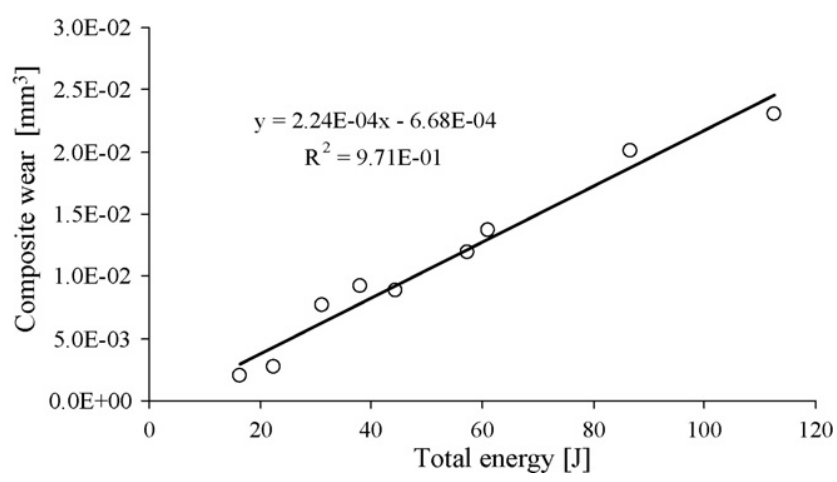

Fig. 6. Representation of total energy and composite wear for the pair glass-composite.

Concerning the pair of materials glass-composite, the energy dissipated by friction was correlated to the material removed by wear (Fig. 6). The wear results of the pair glass-composite fit a linear evolution with high correlation. Considering the energetic approach, the slope of the straight lines (volume ratio/energy, VRE) represents the removed amount of composite volume by unity of energy. The VRE obtained for the glass-composite pair is $2.24 \times 10^{-4} \mathrm{~mm}^{3} / \mathrm{J}$.

Fig. 7 is similar to Fig. 6; however, it correlates the amount of antagonist material removed by wear as a function of the energy dissipated for the pair glass-composite.

In what concerns the morphology of the composite and the glass spheres, the appearance of the surfaces is analogous in all specimens observed. Comparing the different test conditions, no

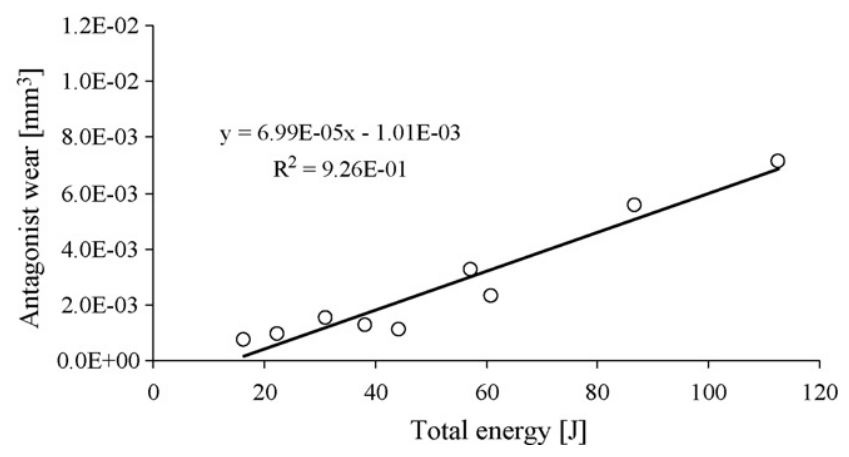

Fig. 7. Representation of total energy and antagonist wear for the pair glass-composite. 
(a)

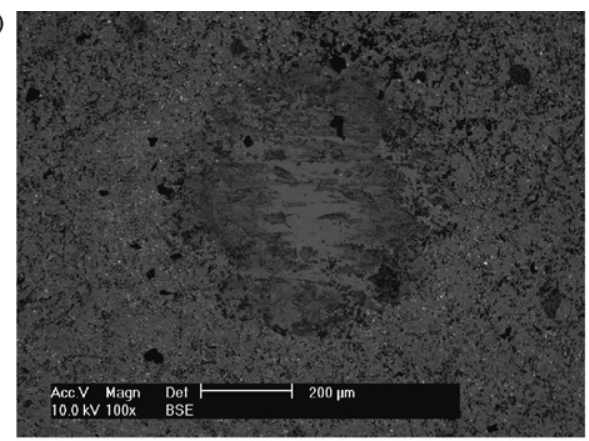

(c)

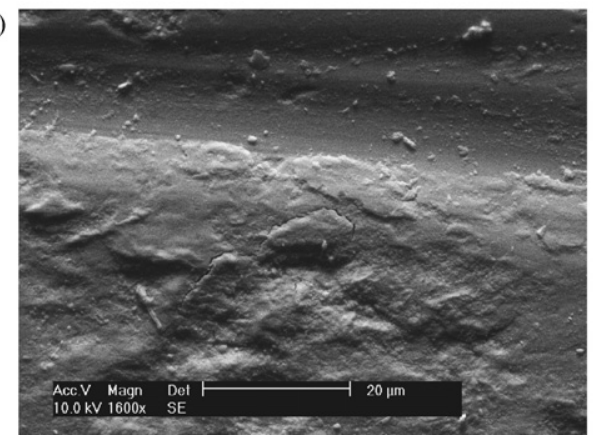

(b)

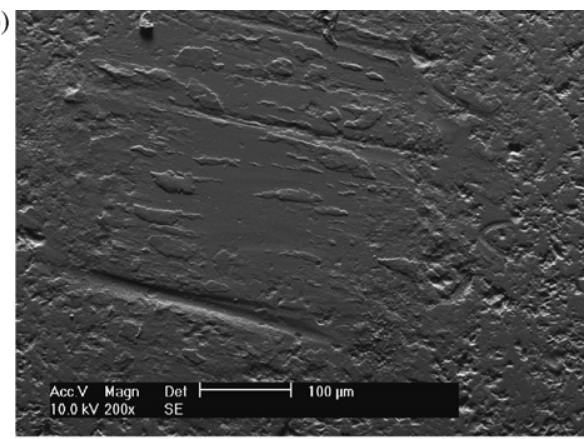

(d)

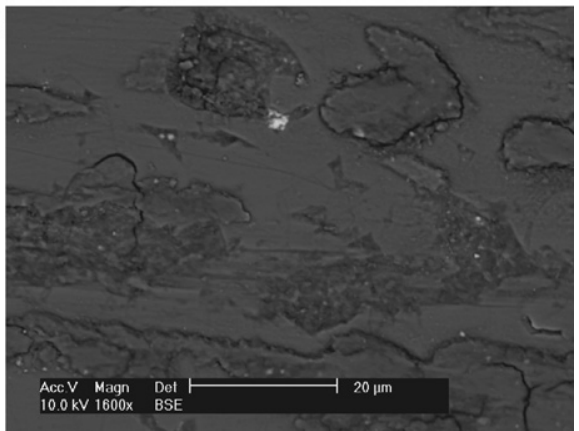

Fig. 8. Morphology of the glass sphere in the reciprocating test $\mathrm{K}$ ( $5 \mathrm{~N}$ and 10,500 cycles): (a) total view of the wear mark, BSE, (b) partial view with SE, (c) ridge with incrusted particles, and (d) Hertzian fractures, BSE.

significant differences were observed. Fig. 8 shows four images from the antagonist body. The morphology of the glass spheres was characterized by few scratches and agglomeration of plasticized material (Fig. 8(b)). In Fig. 8(c) a detail of a scratch is shown, and it is possible to observe adhesion deposition of matrix material onto the composite. These surfaces are also characterized by Hertzian fractures due to the contact of the reinforcement particles trapped between the two surfaces (Fig. 8(d)).
In the last image it is possible to see that the debris of matrix settles preferentially into the series of fractures.

Fig. 9 presents the typical morphology of a composite tested against the glass. The morphology of the composite was characterized by a continuous removal process of matrix and reinforcement particles, with almost no evidence of the detachment of large particles. Fig. 9(a) presents the wear mark correspondent to the reciprocating test $\mathrm{K}(5 \mathrm{~N}$ and 10,500
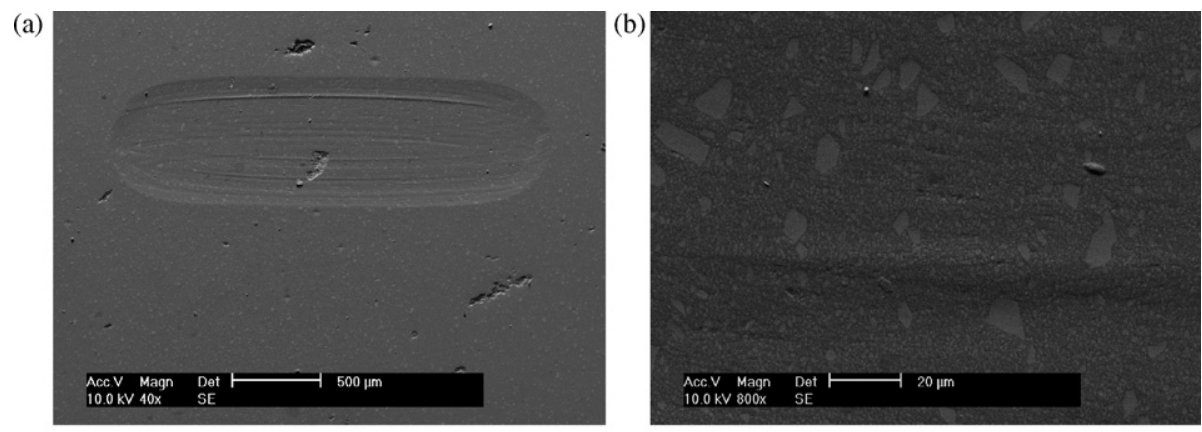

(c)

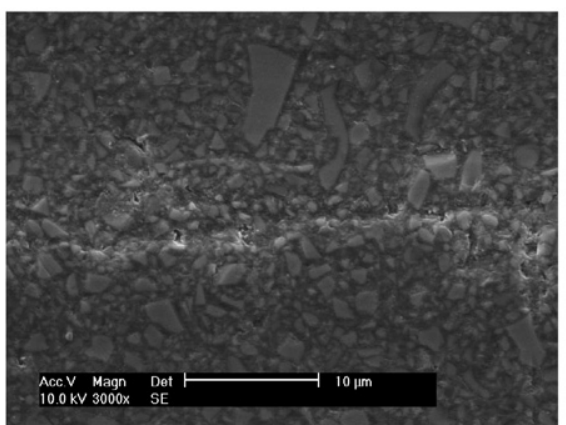

Fig. 9. Morphology of the composite in the reciprocating test $\mathrm{K}$ ( $5 \mathrm{~N}$ and 10,500 cycles): (a) total view of the wear mark, (b) partial view, and (c) small scratch and degradation of the interface particle-matrix. 


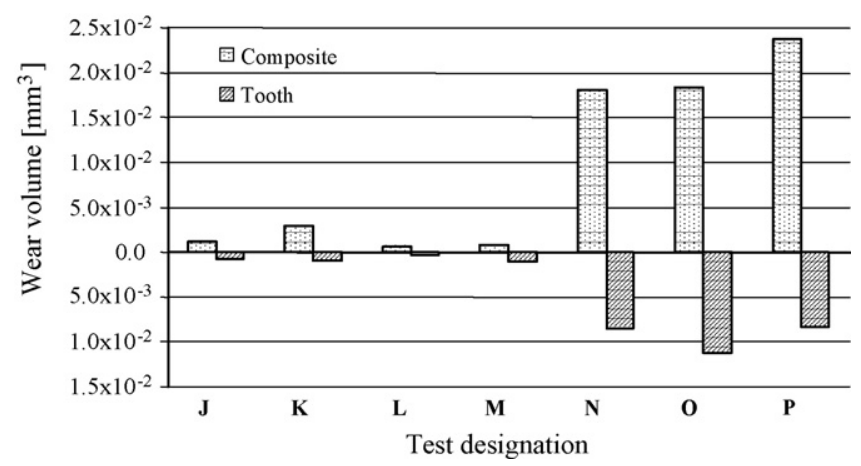

Fig. 10. Wear volumes of the restorative material and antagonist body, tooth, reciprocating test with distillate water.

cycles); a small defect is present in the middle of the scar. Although in Fig. 9(c) it is possible to observe the initial stage of removal of small particles, there is not any transition from a mild to severe regimes. It is also possible to observe a scratch due to a particle trapped between the two surfaces, possibly originated by a detachment of a particle from the composite.

\subsection{Pair tooth-composite}

Fig. 10 represents the same type of graphic, as Fig. 4, but now for the reciprocating test for the pair of materials composite versus tooth. Test conditions $\mathrm{J}, \mathrm{K}, \mathrm{L}$, and $\mathrm{M}$ present much smaller wear volumes than the other three conditions, $\mathrm{N}, \mathrm{O}$ and $\mathrm{P}$; this is valid for the composite and for the antagonist body, the tooth. There is not a well-defined tendency as in the glass-composite case, but as before the wear loss of the composite is greater than the one registered in the antagonist body. The condition which presents greater composite wear is $\mathrm{P}(6 \mathrm{~N}$ and 20,000 cycles $)$, but not for the tooth, which has smaller wear than condition $\mathrm{O}$ (8 $\mathrm{N}$ and 12,000 cycles).

In Table 6 are represented the average values of the friction coefficient for each one of the wear tests of the pair tooth-composite. Contrarily to what occurs to the pair glass-composite, the pair tooth-composite results do not agree with a linear model. The tests J, K, L and M show average values similar to those of the pair glass-composite, and all smaller than 0.3 , while tests $\mathrm{N}, \mathrm{O}$ and $\mathrm{P}$ present average friction coefficients noticeably higher than 0.3 .

The energy dissipated by friction, for the pair toothcomposite, was correlated to the material removed by wear

Table 6

Representation of friction coefficient for the pair tooth-composite

\begin{tabular}{llll}
\hline Test designation & $\begin{array}{l}\text { Normal } \\
\text { load }(\mathrm{N})\end{array}$ & $\begin{array}{l}\text { Duration } \\
\text { (cycles) }\end{array}$ & $\begin{array}{l}\text { Average friction } \\
\text { coefficient, } \mu\end{array}$ \\
\hline J & 8 & 6,000 & 0.29 \\
K & 5 & 10,500 & 0.21 \\
L & 6 & 10,000 & 0.18 \\
M & 3 & 20,000 & 0.19 \\
N & 8 & 9,000 & 0.42 \\
O & 8 & 12,000 & 0.58 \\
P & 6 & 20,000 & 0.58 \\
\hline
\end{tabular}

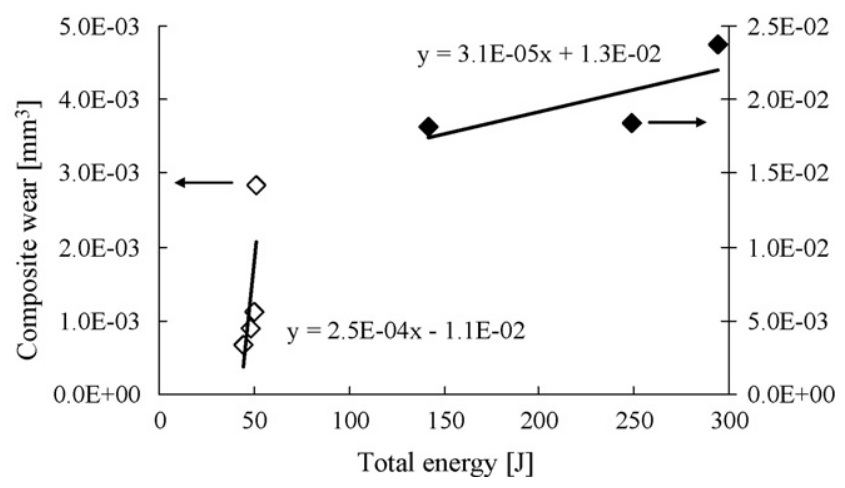

Fig. 11. Representation of total energy and composite wear for the pair tooth-composite.

(Fig. 11). As the values of wear volume vary significantly, the results do not agree with a unique evolution, the tests $\mathrm{J}$, $\mathrm{K}$, $\mathrm{L}$ and $\mathrm{M}$ fitting one linear evolution with a VRE similar to the obtained for glass-composite pair. This evolution is very identical to the one observed for the pair glass-composite and even the slopes of the two tendency lines are similar: $2.24 \times 10^{-4}$ and $2.5 \times 10^{-4} \mathrm{~mm}^{3} / \mathrm{J}$ for the pair glass-composite and teeth-composite, respectively. However, tests N, O and P do not fit the same linear law. These tests show simultaneously significantly higher wear and dissipated energy; the VRE value is one order of magnitude lower than the remaining tests.

Fig. 12 shows the amount of antagonist material removed by wear as a function of the energy dissipated for the pairs tooth-composite. The results reveal the same tendency as for the composite.

Concerning the morphology of the wear surfaces, the features observed on the wear surfaces, from a general point of view, agree with the results presented before. Fig. 13 shows three teeth surfaces resulting from different conditions. Scratches appear in the more severe conditions (Fig. 13(a) and (b)), the number of ridge is higher and in all of the teeth adherent material from the composite can be found. Fig. 13(c) shows the wear mark of the tooth tested M ( $3 \mathrm{~N}$ normal and 20,000 cycles); its surface with fewer scratches permits to explain why the wear volume of the composite is smaller than the condition $8 \mathrm{~N}$ and 9000 cycles.

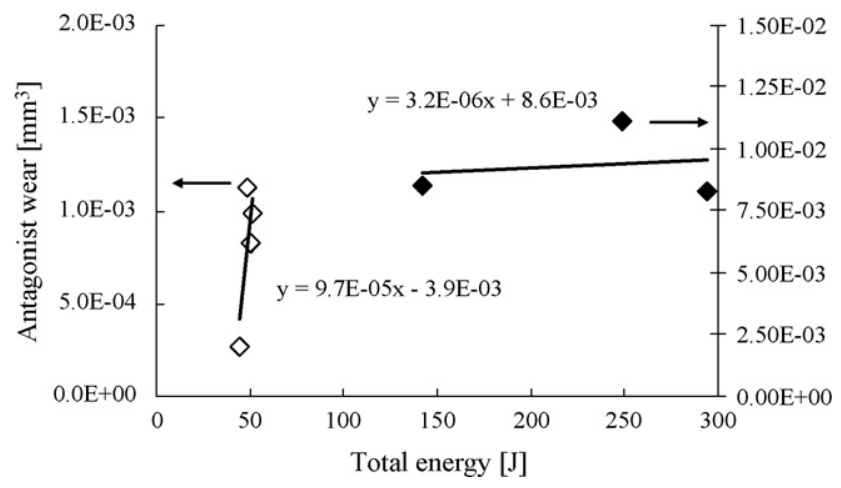

Fig. 12. Representation of total energy and antagonist wear for the pair tooth-composite. 
(a)

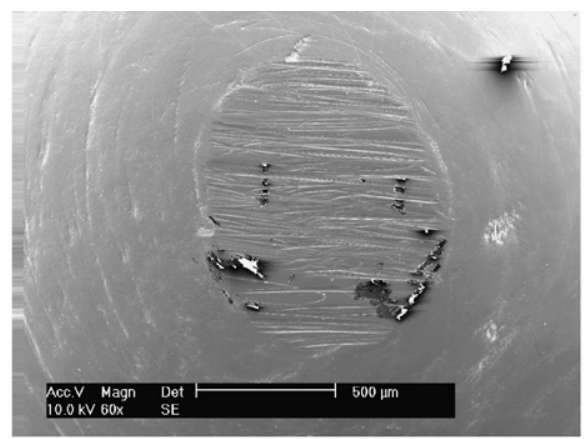

(b)

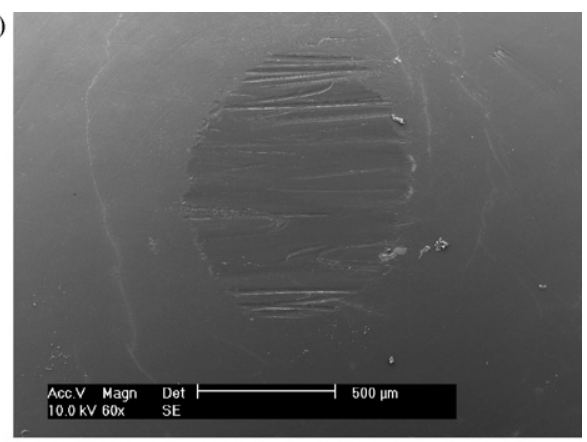

(c)

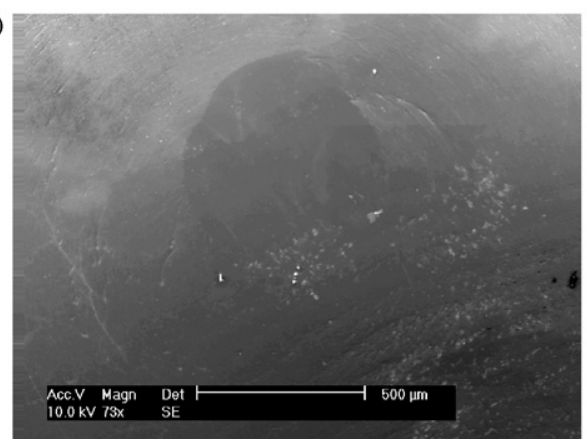

Fig. 13. Morphology of the teeth in the reciprocating tests: (a) $\mathrm{N}$ ( $8 \mathrm{~N}$ and 9000 cycles), (b) O ( $8 \mathrm{~N}$ and 12,000 cycles) and (c) M ( $3 \mathrm{~N}$ and 20,000 cycles).

Concerning the morphology of the composite tested against teeth two types of surfaces have been found; one where the particles are worn along with the matrix, showing a polished surface (Fig. 14(c)), and other where the particles are prominent from the matrix, leading to a rougher surface (region A in Fig. 14(a)). This surface with rough appearance was probably started with scratches as it is evident in Fig. 14(b); this type of wear mark was also observed by Nagarajan et al. [31]. For the test $\mathrm{M}(3 \mathrm{~N}$ and 20,000 cycles), $\mu=0.19$, the wear mark presents almost no scratches and the most common damage is the reinforcement particles break and their removal; otherwise, for more severe test conditions the regions with prominent particles correspond to a higher percentage of the scar area. Tests with smaller normal loads tend to show more reduced removal of reinforcement (a)

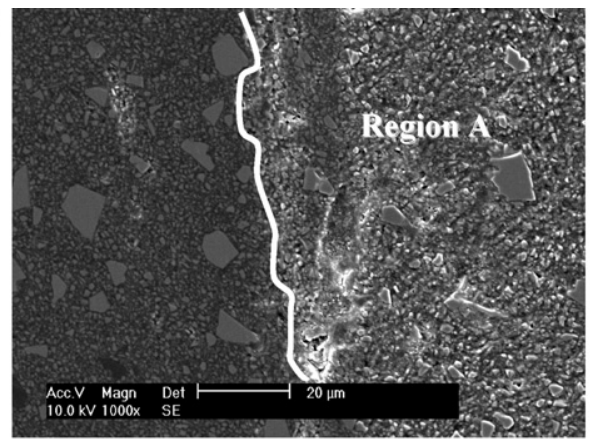

(b)

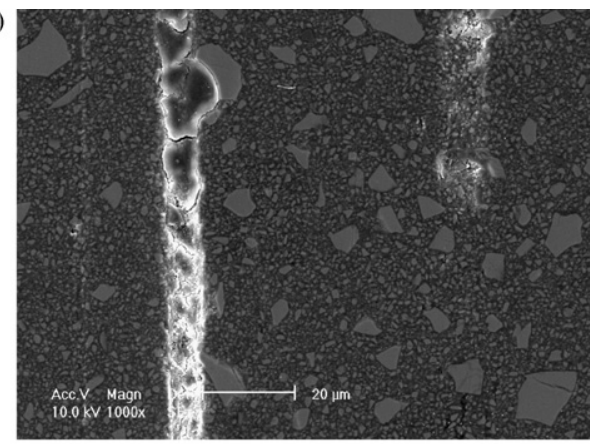

(c)

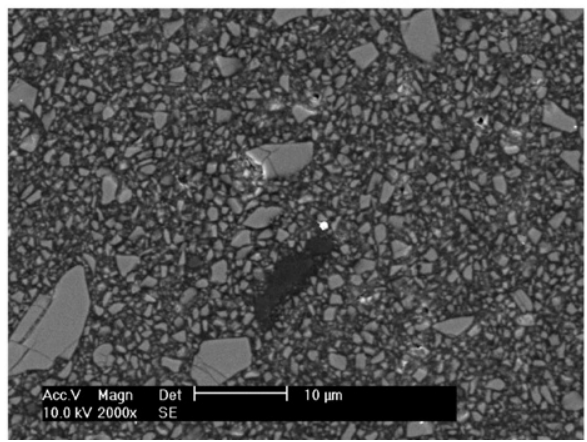

Fig. 14. Morphology of the composite in the reciprocating tests: (a) N ( $8 \mathrm{~N}$ and 9000 cycles), (b) $\mathrm{O}(8 \mathrm{~N}$ and 12,000 cycles) and (c) $\mathrm{M}(3 \mathrm{~N}$ and 20,000 cycles). 
particles, even if with higher test duration (Fig. 14(c)), the intensity of the load being a very important aspect as observed by other investigators $[31,32]$.

\section{Discussion of the results}

The two pair of materials tested reveals a different behaviour. The pair glass-composite display a linear evolution of the wear, with the increase of the energy dissipated, and the morphology of wear shows that the reinforced particles wore together the matrix generating smooth wear scars. For this pair of materials the friction remains always low according to a linear model. The VRE was reasonably constant and a value of $2.24 \times 10^{-4} \mathrm{~mm}^{3} / \mathrm{J}$ fits reasonably all the tested conditions.

On the contrary, the pair teeth-composite displays a transition. For the lower values of normal load, especially with low duration tests, the friction coefficient is low, the wear amount is small and the appearance of wear scars is smooth. However, for more severe test conditions, the friction coefficient is high, the volume of wear is considerable and the wear scars appear rough.

The behaviour observed for the pair teeth-composite is very typical of ceramic materials. In ceramics, the transition from mild to severe wear occurs through a micro-fracture process at the sliding contact. This change is associated to a drastic increase in wear at a critical load that depends on the material and test conditions, namely changes as the load or the coefficient of friction is increased, as reported by Jahanmir [33].

In the case studied the transition in the wear behaviour is associated to a marked change of friction. This fact allows us to explain the transition as a function of the local failure induced by the friction. In the cases where the friction is low, the tangential force between the spherical surface and the composite surface is very low compared to the normal load. Thus in the contact stress distribution, the Hertzian component is predominant, inducing the occurrence of the maximum tangential stress underneath the surface. This stress distribution induces failures beneath the surface by a fatigue process that starts with the initiation of small cracks at the sub-surface and then propagates onto the surface. As this fatigue process requires a long number of cycles, the wear remains low.

However, when the contact conditions are such that the friction between the spherical surface and the composite is strong enough, the stress distribution varies significantly with friction according to contact models, as in Hamilton's model [34]. The major changes in the stress distribution are:

- maximum tangential stress occurs on the surface ahead of the contact;

- maximum tensile stress rises significantly and occurs on the surface beyond the contact.

Both of these reasons justify that for high friction coefficient the failure occurs mainly in surface either by plastic deformation or by fracture. Johnson [35] shows that for a friction coefficient higher than 0.3, the first yield spot moves from beneath towards the surface. This transition value agrees very well with the obtained results. Test conditions $\mathrm{O}, \mathrm{N}$ and $\mathrm{P}$, which lead to friction coefficients higher than 0.3 , revealed a severe wear. For the other test conditions, which lead to friction coefficient values lower than 0.3 , the wear remains mild.

This explanation is emphasized by the fact that for the pair glass-composite, where the friction remains always lowers than 0.3 , the wear was mild for all the tested conditions. The pair glass-composite probably has a similar transition from mild to severe wear. Although a deeper study is needed, it seems that the test conditions, mainly the test duration, were not enough to reach the transition.

\section{Conclusions}

The wear of tooth enamel and glass spheres was investigated on reciprocating contacts against a dental restorative composite. The experimental study has been carried out with several normal loads and duration test.

This study enabled to conclude that:

- The results of the pair glass-composite clearly fit a linear evolution for the friction force. A friction coefficient of $\mu=0.19$ agrees with all the tested conditions.

- For the pair teeth-composite there is a transition from low to high friction. For the less severe tests $(\mu<0.3)$ both pair have identical behaviour and similar values of $\mu$, while for more severe test conditions the friction coefficient is significantly higher.

- The tests of the pair glass-composite lead to smooth wear scars and the evolution of the scar fit a linear evolution with the energy dissipated by friction.

- The pair teeth-composite displays a double wear regime. For less severe test conditions, the wear was low and the wear scars remain smooth. For the most severe test conditions a transition for high wear occurs, leading to rough wear scars.

- The transition from mild to severe wear seems to be due to the evolution of the friction coefficient, which provokes a change of the failure mode.

- Complementary studies are necessary to better determine the transition mild to severe wear on the teeth-composite pair and also to verify if the pair glass-composite displays a similar behaviour.

\section{Acknowledgements}

This work was sponsored by Fundação para a Ciência e a Tecnologia (FCT-Portugal) under the framework of the POCI_2010_program_ERDF (European Regional Development Fund-POCI project/CTM/59858/2004). We would like to acknowledge the valuable help of Prof. Eunice Carrilho, from the Medicine Faculty of the University of Coimbra, on the discussion of the results as well as for supplying the teeth used in the present study. The participation of Dentsply DeTrey Iberica as supplier of the composite material Surefil was most appreciated. 


\section{References}

[1] R. Lewis, R.S. Dwyer-Joyce, Wear of human teeth: a tribological perspective, Proc. Inst. Mech. Eng. J: J. Eng. Tribol. 219 (1) (2005) 2.

[2] E. Sajewicz, On evaluation of wear resistance of tooth enamel and dental materials, Wear 260 (11-12) (2006) 1256-1261.

[3] E.D. Rekov, P. van Thompson, S. Jahanmir, R. Nagarajan, Wear in the unique environment of the mouth, in: Proceedings of the Second Joint American-Eastern European Conference on New Materials and Technologies in Tribology, Infotribo, Gomel, Belarus, 1997, p. 45 (abstract of papers).

[4] K.J.M. Söderholm, D. Sarrett, Y. Abe, M.C.K. Yang, R. Labella, E. Yildiz, G. Willems, Clinical wear performance of eight experimental dental composite over three year determined by two measuring methods, Eur. J. Oral Sci. 109 (2001) 273-281.

[5] J.R. Condon, J.L. Ferracane, Evaluation of composite wear with a new multi-mode oral wear simulator, Dent. Mater. 12 (1996) 218-226.

[6] X. Hu, P.M. Marquis, A.C. Shortall, Two-body in vitro wear study of some current dental composites and amalgams, J. Prosthet. Dent. 82 (2) (1999) 214-220.

[7] S. Suzuki, S.H. Suzuki, C.F. Cox, Evaluating the antagonist wear of restorative materials when placed against human enamel, JADA 127 (1996) 74-80.

[8] J.R. Condon, J.L. Ferracane, In vitro wear of composite with varied cure filler level, and filler treatment, J. Dent. Restor. 76 (7) (1997) 1405-1411.

[9] R.W. Wassel, J.F. McCabe, A.W.G. Walls, Wear characteristics in a twobody wear test, Dent. Mater. 10 (1994) 269-274.

[10] A.J. Gee, R.N.B. Duinen, A. Wener, C.L. Davidson, Early and long-term wear of conventional and resin-modified glass ionomers, J. Dent. Restor. 75 (8) (1996) 1613-1619.

[11] H.H.K. Xu, J.B. Quinn, A.A. Giuseppetti, F.C. Eichmiller, E.E. Parry, G.E. Schumacher, Three-body wear of dental resin composites reinforced with silica-fused whiskers, Dent. Mater. 20 (2004) 220-227.

[12] B.S. Lim, J.L. Ferracane, J.R. Condon, J.D. Adey, Effect of filler fraction and filler surface treatment on wear of microfilled composites, Dent. Mater. 18 (2002) $1-11$.

[13] D.E. Ruddell, M.M. Maloney, J.Y. Thompson, Effect of novel filler particles on the mechanical and wear properties of dental composites, Dent. Mater. 18 (2002) 72-80.

[14] J.W. Kim, K.T. Jang, S.H. Lee, C.C. Kim, S.H. Hahn, F.G. Godoy, Effect of curing method and curing time on the microhardness and wear of pit and fissure sealents, Dent. Mater. 18 (2002) 120-127.

[15] C. Zantner, A.M. Kielbassa, P. Martus, K.H. Kunzelmann, Sliding wear of 19 commercially available composites and compomers, Dent. Mater. 20 (2004) 277-285.

[16] V.S. Nagarajan, S. Jahanmir, V.P. Thompson, In vitro contact wear of dental composites, Dent. Mater. 20 (2004) 63-71.
[17] L.A. Flanders, J.B. Quinn, O.C. Wilson, I.K. Lloyd, Scratch hardness and chipping of dental ceramics under different environments, Dent. Mater. 19 (2003) 716-724.

[18] G. Williems, Multi standard criteria for the selection of potential posterior composites, $\mathrm{PhD}$ Thesis, Katholieke Universiteit Leuven, 1992, p. 76.

[19] J. Zheng, Z.R. Zhou, J. Zhang, H. Li, H.Y. Yu, On the friction and wear behaviour of human tooth enamel and dentin, Wear 225 (2003) 967-974.

[20] H. Li, Z.R. Zhou, Wear behavior of human teeth in dry and artificial saliva conditions, Wear 249 (2002) 980-984.

[21] K. Kawai, K.F. Leinfelder, In vitro evaluation of OCA wear resistance of posterior composites, Dent. Mater. 11 (1995) 246-251.

[22] K.F. Leinfelder, S. Suzuki, In vitro wear device for determining posterior composite wear, JADA 130 (1999) 1347-1353.

[23] S.W. Han, T.A. Blanchet, Experimental evaluation of a steady-state model for the wear of particle-filled polymer composite materials, J. Tribol. 4 (1997) 694-699.

[24] P. Lambrechts, E. Debels, K.V. Landuyt, M. Peumans, B.V. Meerbeek, How to simulate wear? Overview of existing methods, Dent. Mater. 22 (8) (2006) 693-701.

[25] D. Dowson, History of Tribology, Professional Engineering Publishing Limited, London, UK, 1998, p. 577.

[26] B. Blanpain, J.-P. Celis, J.R. Roos, J. Ebberink, J. Smeets, A comparative study of the fretting wear of hard carbon coatings, Thin Solid Films 223 (1993) 65-67.

[27] P.V. Antunes, A. Ramalho, Study of abrasive resistance of composites for dental restoration by ball-cratering, Wear 255 (2003) 990-998.

[28] H. Czicos, Tribology: a system approach to the science and technology of friction, lubrication and wear, Wear 54 (1) (1979) 193 (Elsevier, Amsterdam, 1978)

[29] M.Z. Huq, J.-P. Celis, Expressing wear rate in sliding contacts based on dissipated energy, Wear 252, 375-383.

[30] A. Ramalho, J.C. Miranda, The relationship between wear and dissipated energy in sliding systems, Wear 260 (2006) 361-367.

[31] V.S. Nagarajan, B.J. Hockey, S. Jahanmir, Contact wear mechanisms of dental composite with high filler content, J. Mater. Sci. 35 (2000) 487-496.

[32] D.J. Indrani, W.D. Cook, F. Televantos, M.J. Tyas, J.K. Harcourt, Fracture toughness of water-aged resin composite restorative materials, Dent. Mater. 11 (1995) 201-207.

[33] S. Jahanmir, Wear transitions and tribochemical reactions in ceramics, Proc Inst. Mech. Eng. J: J. Eng. Tribol. 216 (6) (2002) 371.

[34] G. Hamilton, Explicit equations for the stresses beneath a sliding spherical contact, Proc. IMechE 197C (1983) 53-59.

[35] K.L. Johnson, Contact Mechanics, 1st ed., Cambridge University Press, Cambridge, 1985, pp. 202-210. 